03,05

\title{
Импульсное лазерное облучение светоизлучающих структур со слоем (Ga,Mn)As
}

\author{
(c) Б.Н. Звонков ${ }^{1}$, О.В. Вихрова ${ }^{1}$ ฯ Ю.А. Данилов ${ }^{1}$, П.Б. Демина ${ }^{1}$, М.В. Дорохин ${ }^{1}$, \\ М.Н. Дроздов ${ }^{2}$, Д.А. Здоровейщев ${ }^{1}$, И.Л. Калентьева ${ }^{1}$, Ю.М. Кузнецов ${ }^{1}$, \\ А.В. Кудрин ${ }^{3}$, А.В. Нежданов ${ }^{3}$, А.Е. Парафрин ${ }^{2}$, Д.В. Хомицкий ${ }^{3}$
}

${ }^{1}$ Научно-исследовательский физико-технический институт

Нижегородского государственного университета им. Н.И. Лобачевского,

Нижний Новгород, Россия

${ }^{2}$ Институт фоизики микроструктур РАН,

Нижний Новгород, Россия

${ }^{3}$ Нижегородский государственный университет им. Н.И. Лобачевского,

Нижний Новгород, Россия

E-mail:vikhrova@nifti.unn.ru

Поступила в Редакцию 9 апреля 2021 г.

В окончательной редакции 9 апреля 2021 г.

Принята к публикации 19 апреля 2021 г.

Сочетанием методов МОС-гидридной эпитаксии и импульсного лазерного нанесения изготовлены гетеронаноструктуры InGaAs/GaAs со слоем ( $\mathrm{Ga}, \mathrm{Mn}) \mathrm{As}$ на поверхности, и исследовано влияние воздействия импульсного эксимерного лазера (длина волны $248 \mathrm{~nm}$, длительность импульса $\sim 30 \mathrm{~ns}$, плотность энергии в диапазоне 200-360 mJ $/ \mathrm{cm}^{2}$ ) на их излучательные, структурные и гальваномагнитные свойства. При исследованиях использовалась спектроскопия фотолюминесценции, дополненная возможностью анализа поляризационных характеристик излучения структур. Кристаллическое совершенство исходных и облученных лазером образцов изучалось с использованием спектроскопии комбинационного рассеяния. Элементный состав структур и его распределение по глубине исследовались методом вторичной ионной масс-спектрометрии. Влияние импульсного лазерного отжига на ферромагнитные свойства гетеронаноструктур характеризовалось поведением магнитополевых зависимостей сопротивления Холла и магнетосопротивления при температурах $10-300 \mathrm{~K}$ в диапазоне магнитных полей \pm 3600 Ое. При комнатной температуре исследование проводилось в магнитных полях, достигающих значений \pm 28000 Ое. Для получения расчетных распределений температуры вдоль толщины образца и во времени с применением модели процесса лазерного отжига, основанной на решении задачи о распространении тепла в одномерной GaAs системе с учетом слоя (Ga,Mn)As на поверхности, были использованы оригинальные данные по коэффициенту теплопроводности структур со слоем $(\mathrm{Ga}, \mathrm{Mn}) \mathrm{As}$, полученные посредством модифицированной методики частотного разделения (3$\omega$-метода).

Ключевые слова: МОС-гидридная эпитаксия, импульсное лазерное нанесение, гетеронаноструктура, разбавленный магнитный полупроводник, импульсный лазерный отжиг.

DOI: 10.21883/FTT.2021.09.51247.01H

\section{1. Введение}

Разбавленные магнитные полупроводники и ( $\mathrm{Ga}, \mathrm{Mn}) \mathrm{As}$, в частности, являются перспективными материалами для современной оптической электроники. Ранее нами была показана возможность применения метода импульсного лазерного нанесения (ИЛН) в сочетании с послеростовым импульсным лазерным отжигом (ИЛО) для формирования ( $\mathrm{Ga}, \mathrm{Mn}) \mathrm{As}$ с высокими значениями температуры Кюри $(80-100 \mathrm{~K})$ [1]. При этом импульсный лазерный отжиг слоев ( $\mathrm{Ga}, \mathrm{Mn}) \mathrm{As}$, сформированных методом ИЛН, используется для повышения температуры Кюри от типичных для метода ИЛН значений $30-40 \mathrm{~K}$ до $80-100 \mathrm{~K}$, сопоставимых с мировыми аналогами [2-4]. В работе [5] нами была исследована возможность модифицирования импульсным лазерным отжигом свойств слоя (Ga, Mn)As, расположенного на поверхности квантово-размерной гетероструктуры InGaAs/GaAs, c сохранением ее излучательных свойств. Основное внимание при этом было уделено влиянию лазерного воздействия на фотолюминесцентные характеристики структур с четырьмя квантовыми ямами In GaAs/GaAs, отличающимися содержанием индия и расположенными на различном расстоянии от слоя ( $\mathrm{Ga}, \mathrm{Mn}) \mathrm{As}$. Для описания полученных результатов была использована модель процесса лазерного отжига, представляющая собой решение задачи о распространении тепла в одномерной системе на основе GaAs с учетом присутствия слоя ( $\mathrm{Ga}, \mathrm{Mn}) \mathrm{As}$ на поверхности. В настоящей работе помимо более полного анализа излучательных свойств подобных гетеронаноструктур, включающего в себя измерение поляризационных характеристик излучения квантовых ям, расположенных на различном расстоянии от слоя (Ga, Mn)As, представлены результаты комплексных 
исследований влияния импульсного лазерного отжига на структурные, транспортные и магнитные свойства.

\section{2. Методика эксперимента}

Исследовались квантово-размерные структуры InGaAs/GaAs со слоем (Ga, Mn)As в качестве спинового инжектора на поверхности. Особенностью исследованных структур является близкое расположение (от $\sim 10 \mathrm{~nm})$ напряженных квантовых ям к подвергавшемуся импульсному лазерному воздействию слою (Ga, Mn)As. Структуры изготавливались комбинированным методом МОС-гидридной эпитаксии (МОСГЭ) и импульсного лазерного нанесения на пластинах полуизолирующего $\mathrm{GaAs}(100)$ и содержали четыре квантовые ямы (КЯ) $\operatorname{In}_{x} \mathrm{Ga}_{1-x} \mathrm{As} / \mathrm{GaAs}$, отличающиеся содержанием индия $(0.08 \leq x \leq 0.25)$ и расположенные на различном расстоянии от слоя $(\mathrm{Ga}, \mathrm{Mn}) \mathrm{As}$ толщиной 50-100 nm. Схема поперечного сечения структур показана на вставке к рис. 1. Буферный слой GaAs толщиной 300-400 nm, четыре квантовые ямы (QW) $\mathrm{InGaAs} / \mathrm{GaAs}$ (толщина слоя $\mathrm{In}_{x} \mathrm{Ga}_{1-x} \mathrm{As} \sim 10 \mathrm{~nm}$, толщина барьера $\mathrm{GaAs}=50 \mathrm{~nm}$ ) и спейсерный слой GaAs толщиной $\sim 10 \mathrm{~nm}$ выращивались при температурах $600-650^{\circ} \mathrm{C}$ методом МОСГЭ при атмосферном давлении. Для ближайшей к слою $(\mathrm{Ga}, \mathrm{Mn}) \mathrm{As}$ квантовой ямы QW1 значение $x$ составляло 0.25 , для второй от поверхности QW2 $x \sim 0.18$, далее третьей и четвертой квантовым ямам QW3 и QW4 соответствовали величины $x \sim 0.11$ и $x \sim 0.08$. Затем температура понижалась до $330^{\circ} \mathrm{C}$, и методом импульсного лазерного нанесения при пониженном давлении формировался слой (Ga, Mn)As. Содержание марганца в разбавленном магнитном полупроводнике ( $\mathrm{Ga}, \mathrm{Mn}) \mathrm{As}$ определялось соотношением времен распыления мишеней $\mathrm{Mn}$ и $\mathrm{GaAs}$ $\left(t_{\mathrm{Mn}} / t_{\mathrm{GaAs}}\right)$ и составляло $Y_{\mathrm{Mn}}=t_{\mathrm{Mn}} /\left(t_{\mathrm{GaAs}}+t_{\mathrm{Mn}}\right)=0.13$.

Образцы изготовленных структур подвергались воздействию расфокусированного пучка излучения импульсного эксимерного лазера LPX-200 (рабочая смесь $\mathrm{KrF}$, длина волны $248 \mathrm{~nm}$, длительность импульса $\sim 30 \mathrm{~ns})$. При этом плотность энергии варьировалась в диапазоне от 200 до $360 \mathrm{~mJ} / \mathrm{cm}^{2}$.

Кристаллическое совершенство исходных и облученных лазером образцов изучалось с использованием спектроскопии комбинационного рассеяния. Спектры комбинационного рассеяния света (КРС) исследованы на комплексе NTEGRA Spectra производства NT-MDT с применением лазера с длиной волны $473 \mathrm{~nm}$. Излучение фокусировалось объективом $100 \times$ с апертурой $\mathrm{NA}=0.9$. Мощность лазерного излучения, измеренная с помощью кремниевого фотодетектора 11PD100-Si (Standa Ltd), составляла $0.5 \mathrm{~mW}$. Исследование спектров КРС проводились в геометрии обратного рассеяния. Спектроскопия КРС осуществлялась в диапазоне $50-900 \mathrm{~cm}^{-1}$ с разрешением $0.7 \mathrm{~cm}^{-1}$. Все спектры были получены при комнатной температуре. Время экспозиции составляло $120 \mathrm{~s}$.

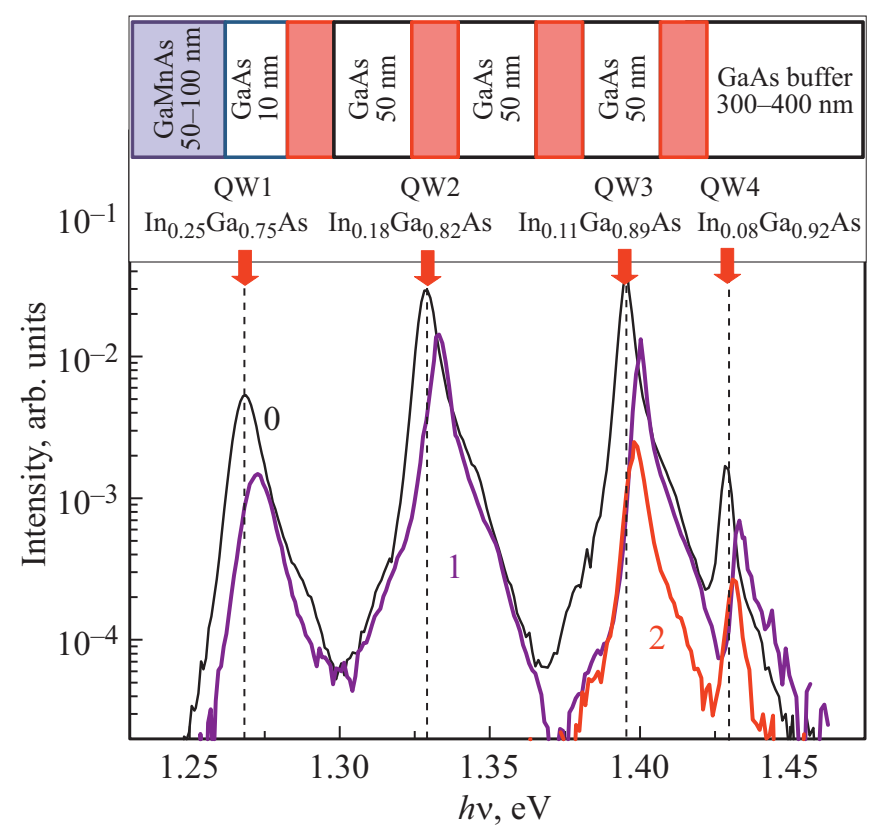

Рис. 1. Спектры ФЛ (77 К) структур с четырьмя КЯ и слоем (Ga, Mn)As на поверхности: (0) - исходный образец; (1) $P=300 \mathrm{~mJ} / \mathrm{cm}^{2} ;(2)-P=360 \mathrm{~mJ} / \mathrm{cm}^{2}$. На вставке показана схема поперечного сечения структуры.

Элементный состав исходных и отожженных образцов и его распределение по глубине изучались методом вторичной ионной масс-спектрометрии (ВИМС). Послойный анализ проводился с использованием распыляющих пучков ионов $\mathrm{O}_{2}$ или $\mathrm{Cs}$ и анализирующего пучка ионов Вi. Глубина и размеры кратеров травления измерялись с помощью интерференционного микроскопа Talysurf CCI 2000 (Центр коллективного пользования ИФМ РАН). Принцип работы данного прибора описан в [6]. Полученные профили распределения атомов представляли собой зависимости интенсивности счета (числа импульсов в секунду) от времени распыления. Затем, после измерения глубины соответствующих кратеров, были получены ВИМС профили компонентов.

Исследовались температурные зависимости коэффициента теплопроводности исходных образцов структур со слоем ( $\mathrm{Ga}, \mathrm{Mn}) \mathrm{As}$ на поверхности. Для исследования применялась модифицированная методика частотного разделения ( $3 \omega$-метод), заключающаяся в регистрации частотной зависимости напряжения двух структур: подложка и подложка с исследуемой пленкой [7]. Величина коэффициента теплопроводности пленки определяется из разности двух полученных частотных характеристик. Измерения проводились на специально сформированных с применением электронно-лучевого испарения в вакууме (формирование металлического контакта), фотолитографии и химического травления меза-структурах, представляющих собой тонкую $(\sim 3 \mathrm{~nm})$ полоску длиной $\sim 3 \mathrm{~cm}$ и шириной $\sim 20 \mu \mathrm{m}$. Через полоску пропускается электрический ток фиксированной частоты $\omega$. 
Вследствие этого происходит разогрев металлической полоски и распространение части тепла вглубь структуры, которое определяется коэффициентом теплопроводности образца. В результате меняется сопротивление металлической полоски, что приводит к нелинейному искажению пропускаемого электрического сигнала и появлению дополнительных гармоник. Информативной в плане коэффициента теплопроводности исследуемого образца является третья гармоника падающего на полоске напряжения $U_{3 \omega}$. В ходе эксперимента регистрируется частотная характеристика напряжения на третьей гармонике. Оригинальная автоматизированная установка для исследований температурной зависимости коэффициента теплопроводности включала в себя источник тока Keithley-6221, селективный вольтметр Stanford 810 SR и размещенные в вакуумной камере графитовый столик-нагреватель и галогеновые лампы накаливания, используемые для нагрева.

Исследования гальваномагнитных свойств структур, спектров фотолюминесценции (ФЛ) и поляризационных характеристик ФЛ излучения проводились с использованием гелиевого криостата замкнутого цикла Janis CCS-300S/202 при температурах $10-300 \mathrm{~K}$ в диапазоне магнитных полей \pm 3600 Ое. При комнатной температуре сопротивление Холла и магнетосопротивление изучались в магнитных полях, достигающих значений \pm 28000 Oe $(2.8 \mathrm{~T})$.

\section{3. Результаты и обсуждение}

Излучательные свойства (фотолюминесценция) исходного образца и отожженных лазером образцов гетеронаноструктуры со слоем ( $\mathrm{Ga}, \mathrm{Mn}) \mathrm{As}$ толщиной около $100 \mathrm{~nm}$ представлены на рис. 1. Спектр ФЛ исходного образца содержит четыре пика в области энергий кванта $1.27,1.33,1.4$ и $1.43 \mathrm{eV}$, отвечающих основным излучательным переходам в квантовых ямах QW1, $\mathrm{QW} 2$, QW3 и QW4, соответственно. Видно, что при плотности энергии лазерного облучения $300 \mathrm{~mJ} / \mathrm{cm}^{2}$ интенсивность излучения квантовых ям уменьшается в 3-4 раза, вместе с тем удается сохранить излучательные свойства всех квантовых ям, в том числе и КЯ $\mathrm{QW} 1$, расположенной на расстоянии $10-12 \mathrm{~nm}$ от слоя ( $\mathrm{Ga}, \mathrm{Mn})$ As. Ширина пиков практически не изменяется, a их положение немного смещается в область бо́льших энергий. С увеличением плотности энергии в импульсе до величины $\sim 360 \mathrm{~mJ} / \mathrm{cm}^{2}$ регистрируется полное гашение излучения ФЛ квантовых ям QW1 и QW2 и наблюдается значительное (более чем на порядок величины) уменьшение интенсивности ФЛ для квантовых ям QW3 и QW4. Наблюдаемые изменения в спектрах ФЛ позволяют объяснить данные исследований образцов методом вторичной ионной масс-спектрометрии (рис. 2).

Сопоставляя ВИМС профили атомов In, Ga и $\mathrm{Mn}$ в исходном и отожженном лазером (с плотностью энергии
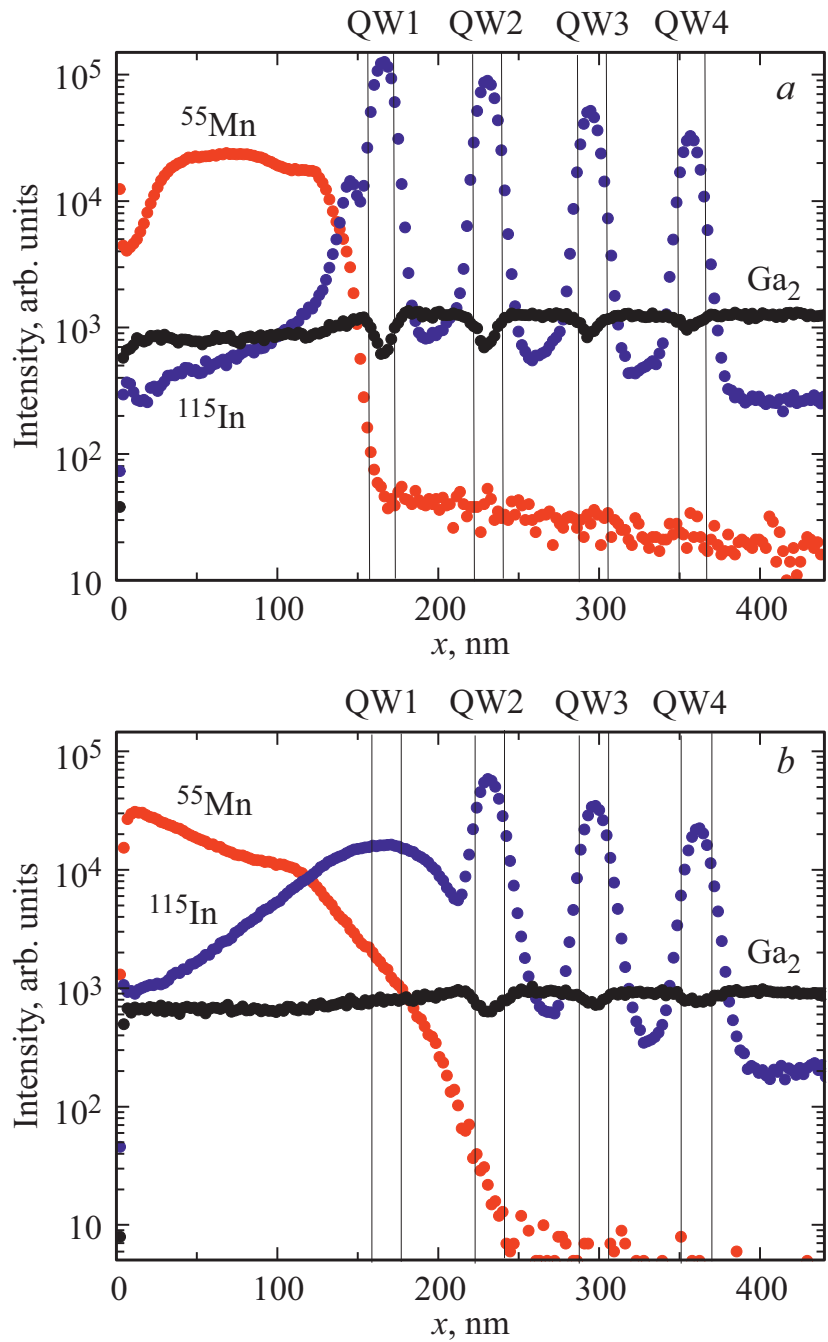

Рис. 2. ВИМС профили атомов $\mathrm{Mn}$, In и $\mathrm{Ga}$ в исходном образце $(a)$ и образце, отожженном эксимерным лазером с плотностью энергии $360 \mathrm{~mJ} / \mathrm{cm}^{2}(b)$.

$360 \mathrm{~mJ} / \mathrm{cm}^{2}$ ) образцах (рис. $2, a$ и рис. $2, b$ соответственно) можно отметить следующие изменения:

- наблюдается значительное диффузионное расплывание индия (в особенности в области квантовой ямы QW1), приводящее к нарушению резкости гетерограниц InGaAs/GaAs и увеличению ширины квантовых ям в отожженном образце;

- атомы марганца в исходном образце сосредоточены в слое $(\mathrm{Ga}, \mathrm{Mn}) \mathrm{As}$ (толщиной около $110 \mathrm{~nm}$ по данным ВИМС) и профиль Мn выглядит достаточно резким;

- для отожженного образца наблюдается накопление атомов $\mathrm{Mn}$ у поверхности слоя $(\mathrm{Ga}, \mathrm{Mn}) \mathrm{As}$ и проникновение вглубь структуры вплоть до квантовой ямы QW2.

Причиной таких диффузионных процессов является значительное тепловое воздействие, возникающее вследствие поглощения лазерного излучения. Основная часть излучения эксимерного лазера с длиной волны $248 \mathrm{~nm}$ поглощается в тонком приповерхностном слое $(\mathrm{Ga}, \mathrm{Mn}) \mathrm{As}$ (около 5-10 nm), происходит его разогрев 
и дальнейшее распространение тепла вглубь структуры. Как было показано нами ранее [5] с использованием модели процесса лазерного отжига, основанной на решении задачи о распространении тепла в одномерной $\mathrm{GaAs}$ системе с учетом слоя $(\mathrm{Ga}, \mathrm{Mn}) \mathrm{As}$ на поверхности, в области расположения квантовых ям QW1 и QW4 температуры достигают значений около 1125 и $975 \mathrm{~K}$, соответственно, для плотности энергии лазерного излучения $360 \mathrm{~mJ} / \mathrm{cm}^{2}$. Указанные температуры значительно превышают температуры изготовления гетеронаноструктур и могут способствовать диффузионному перемешиванию элементов III группы на гетерограницах InGaAs/GaAs. Кроме того, низкотемпературный слой (Ga, Mn)As с такой значительной концентрацией $\mathrm{Mn}$ (выше 10 at.\%) содержит точечные дефекты и избыточный марганец в междоузлиях. В результате теплового воздействия происходит диффузия дефектов и атомов марганца вглубь структуры, приводящая к расплыванию границ квантовых ям. Вследствие таких процессов усиливается безизлучательная рекомбинация и регистрируется сначала, при меньших плотностях энергии лазерного излучения, уменьшение ФЛ сигнала всех квантовых ям, а затем и полное его гашение для квантовых ям, ближайших по расположению к слою $(\mathrm{Ga}, \mathrm{Mn}) \mathrm{As}$ (QW1 и QW2), и сильное уменьшение фотолюминесценции КЯ QW3 и QW4.

Анализ спектров комбинационного рассеяния света исходного и отожженного лазером образцов с использованием аппроксимации их лоренцианами показал наличие пиков в области LO- и TO-мод GaAs и связанную фонон-плазмонную моду (CPLP) (вставка на рис. 3). Причиной появления CPLP-моды являются сильнозатухающие продольные колебания плазмонов, которые взаимодействуют с LO-фононами через их макроскопические электрические поля. Для отожженных лазером образцов наблюдается уменышение интенсивности пиков LO- и TO-мод, смещение их в область меньших частот и уширение по отношению к аналогичным пикам в спектре исходного образца. Такое поведение обусловлено разупорядочением, характеризующимся ослаблением связей и отклонениями от трансляционной симметрии, то есть эффектами, возникающими при формировании твердого раствора (Ga, Mn)As [8,9]. При этом интенсивность CPLP-моды значительно возрастает и происходит ее смещение в область низких частот (рис. 3). Это свидетельствует об усилении фонон-плазмонного взаимодействия в слое $(\mathrm{Ga}, \mathrm{Mn}) \mathrm{As}$ благодаря возрастанию концентрации носителей заряда (дырок) вследствие импульсного лазерного отжига. Данный результат подтверждается измерениями эффекта Холла при $300 \mathrm{~K}$, согласно которым для подвергавшихся импульсному лазерному воздействию $\left(P=300 \mathrm{~mJ} / \mathrm{cm}^{2}\right)$ образцов регистрируется возрастание объемной концентрации дырок от $6.8 \cdot 10^{19}$ до $2.8 \cdot 10^{20} \mathrm{~cm}^{-3}$, при этом подвижность носителей заряда остается низкой и составляет $\sim 4 \mathrm{~cm}^{2} / \mathrm{V} \cdot \mathrm{s}$.

Таким образом, в результате лазерного воздействия, кроме изменений в излучательных характери-

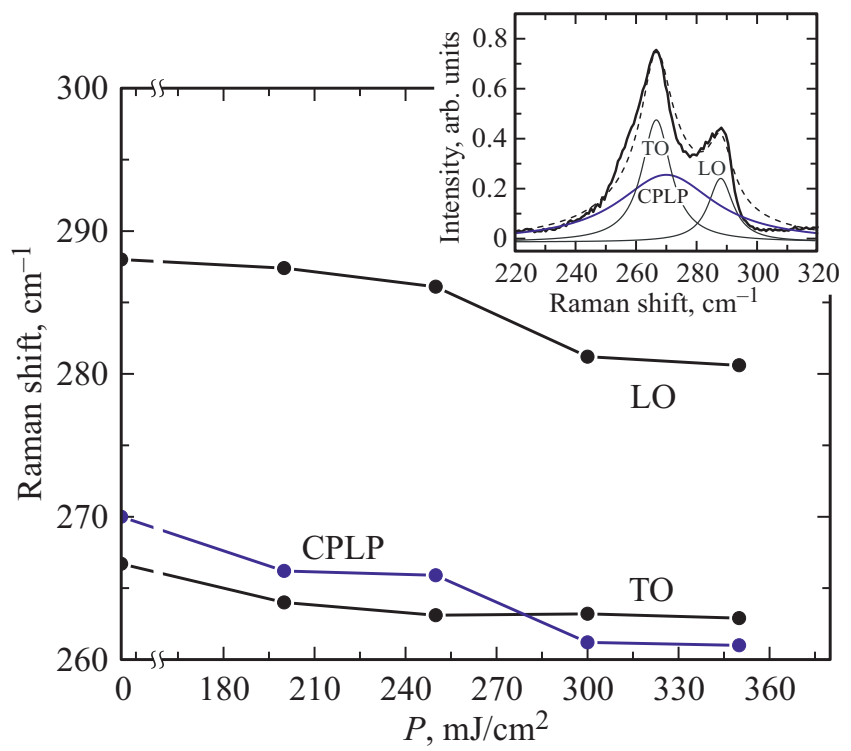

Pис. 3. Положение пиков в области LO-моды и TO-моды GaAs и связанной фонон-плазмонной моды (CPLP), полученное посредством аппроксимации спектров комбинационного рассеяния лоренцианами, для исходного и отожженных образцов. На вставке показан спектр комбинационного рассеяния исходного образца структуры.

стиках квантовых ям, наблюдается повышение электрической активации легирующей примеси. Исходный слой $(\mathrm{Ga}, \mathrm{Mn}) \mathrm{As}$, выращенный при достаточно низкой температуре $\left(330^{\circ} \mathrm{C}\right)$, может содержать значительное количество вакансий галлия $\left(V_{\mathrm{Ga}}\right)$. При наносекундном лазерном нагреве слоя может происходить взаимное диффузионное перемещение на короткие расстояния (несколько нанометров) вакансий галлия и атомов $\mathrm{Mn}$, находящихся первоначально в нерегулярных положениях (например, в междоузлиях, $\mathrm{Mn}_{\mathrm{i}}$ ) в решетке полупроводника. В результате реакции $V_{\mathrm{Ga}}+\mathrm{Mn}_{\mathrm{i}}=\mathrm{Mn}_{\mathrm{Ga}}$ увеличивается суммарная электрическая активация атомов марганца в слое $(\mathrm{Ga}, \mathrm{Mn}) \mathrm{As}$ и, как следствие, возрастает концентрация носителей заряда (дырок).

Температурные зависимости сопротивления исходного и отожженных лазером образцов свидетельствуют о значительном возрастании (на два порядка величины в области температур ниже $50 \mathrm{~K}$ ) проводимости слоя ( $\mathrm{Ga}, \mathrm{Mn}) \mathrm{As}$ после воздействия лазерного излучения во всем диапазоне температур измерения (рис. 4 и вставка к нему). Из представленных данных видно, что с увеличением плотности энергии излучения от 200 (кривая 1) до 250 (кривая 2) и далее до $300 \mathrm{~mJ} / \mathrm{cm}^{2}$ (кривая 3) сопротивление структур уменьшается на всем температурном диапазоне измерений. Зависимости $R(T)$ содержат максимумы: ярко выраженный, как в случае образца, отожженного с $P=200 \mathrm{~mJ} / \mathrm{cm}^{2}$, и менее заметные для других отожженных образцов (кривые 2 и 3). Температуру, отвечающую такому максимуму, соотносят с температурой фазового перехода ферромагнетик-пара- 


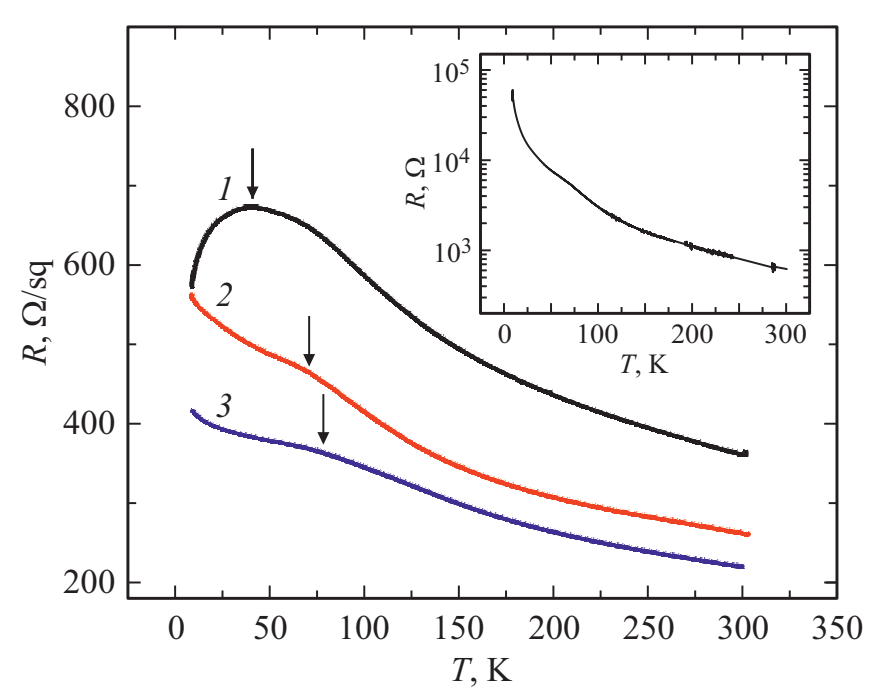

Рис. 4. Температурные зависимости сопротивления для образцов, отожженных эксимерным лазером с плотностью энергии 200 (кривая 1), 250 (кривая 2) и $300 \mathrm{~mJ} / \mathrm{cm}^{2}$ (кривая 3). Стрелками показаны возможные значения температур фазового перехода ферромагнетик-парамагнетик. На вставке приведена зависимость сопротивления от температуры для исходного образца структуры.

магнетик (температурой Кюри, $T_{\mathrm{C}}$ ) [10]. На рис. 4 предполагаемые температуры Кюри отмечены стрелками, и можно считать, что с увеличением плотности лазерного излучения при отжиге $T_{\mathrm{C}}$ возрастает.

Об изменении магнитных свойств гетеронаноструктур со слоем ( $\mathrm{Ga}, \mathrm{Mn}) \mathrm{As}$ вследствие воздействия лазерного излучения свидетельствует поведение магнитополевых зависимостей сопротивления Холла и магнетосопротивления. На вставке к рис. 5, a приведена магнитополевая зависимость сопротивления Холла исходного образца при $20 \mathrm{~K}$, которая характеризуется петлей гистерезиса с малым значением коэрцитивного поля $\left(H_{\mathrm{C}} \sim 70 \mathrm{Oе}\right)$. При температурах свыше $40 \mathrm{~K}$ зависимость $R_{\mathrm{H}}(H)$ становится линейной. Магнитополевая зависимость сопротивления Холла образца, отожженного при $P=250 \mathrm{~mJ} / \mathrm{cm}^{2}$, в случае температуры измерений $10 \mathrm{~K}$ является нелинейной с почти квадратной петлей гистерезиса $\left(H_{\mathrm{C}} \sim 850 \mathrm{Oe}\right)$. С повышением температуры до 60-70 К происходит уменьшение коэрцитивного поля до 250-300 Ое (рис. 5, a). Для температуры $80 \mathrm{~K}$ наблюдается „гистерезис с осиной талией“ $[11]$, затем при повышении температуры до $100 \mathrm{~K}$ на зависимости $R_{\mathrm{H}}(H)$ вновь присутствует петля гистерезиса с коэрцитивным полем около 300 Ое. Далее с увеличением температуры до $250 \mathrm{~K}$ сохраняется нелинейная (без гистерезиса) зависимость сопротивления Холла от магнитного поля, изменяющегося в диапазоне \pm 3600 Ое. Магнитополевая зависимость холловского сопротивления отожженного образца, полученная в больших полях (до \pm 28000 Ое) при комнатной температуре, имела нелинейный вид с петлей гистерезиса $\left(H_{\mathrm{C}} \sim 1050 \mathrm{Oе}\right)$. Перечисленные осо- бенности поведения зависимостей $R_{\mathrm{H}}(H)$ с увеличением температуры и диапазона магнитного поля при измерении, а именно, появление петли гистерезиса с „осиной талией“ и влияние диапазона изменения внешнего магнитного поля на вид зависимости, свидетельствуют о наличии в слое (Ga, Mn)As двух ферромагнитных фаз, отличающихся температурой Кюри. Для представленного на рис. 5 случая, предположительно, одна из фаз имеет $T_{\mathrm{C}} \sim 70-80 \mathrm{~K}$, а вторая - температуру Кюри выше комнатной.

Зависимости магнетосопротивления от магнитного поля для исходного образца гетероструктуры для температуры $20 \mathrm{~K}$ и для образца, отожженного лазером при $P=250 \mathrm{~mJ} / \mathrm{cm}^{2}$, показаны на рис. $5, b$. Отрицательное магнетосопротивление (ОМС) исходного образца имеет гистерезисный вид, а его величина достигает 10\% в
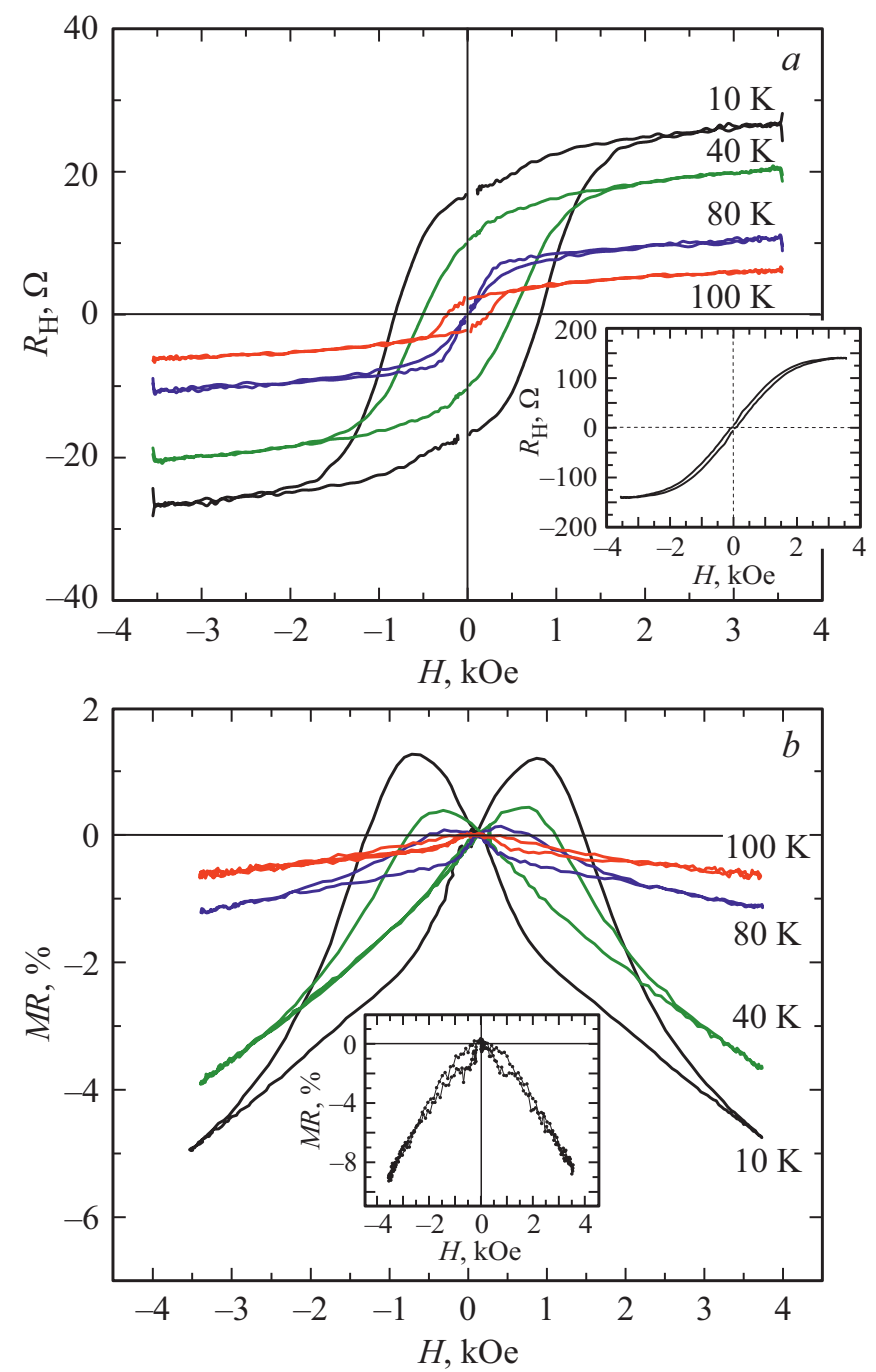

Рис. 5. (a) Магнитополевые зависимости сопротивления Холла и $(b)$ зависимости магнетосопротивления от магнитного поля при различных температурах для образца, отожженного лазером при $P=250 \mathrm{~mJ} / \mathrm{cm}^{2}$. На вставках приведены магнитополевые зависимости сопротивления Холла и магнетосопротивления исходного образца при $20 \mathrm{~K}$. 
магнитном поле \pm 3600 Ое (вставка на рис. $5, b)$. В результате импульсного лазерного воздействия магнитополевые зависимости существенным образом модифицируются, величина ОМС уменьшается, и появляются области положительного магнетосопротивления. Такое поведение является характерным для ферромагнитных материалов и $(\mathrm{Ga}, \mathrm{Mn}) \mathrm{As}$, в частности, и объясняется появлением эффекта анизотропного магнетосопротивления [12]. С повышением температуры измерений величина положительного магнетосопротивления снижается и уменьшается область магнитных полей, где оно регистрируется. На зависимости для температуры $100 \mathrm{~K}$ участок положительного магнетосопротивления отсутствует. Наблюдаемые изменения в характере магнитополевых зависимостей сопротивления также подтверждают изменение магнитных свойств слоя $(\mathrm{Ga}, \mathrm{Mn}) \mathrm{As}$ после импульсного лазерного воздействия.

Для анализа модификации свойств гетеронаноструктур со слоем $(\mathrm{Ga}, \mathrm{Mn}) \mathrm{As}$ на поверхности при импульсном лазерном отжиге были получены расчетные значения распределения температуры в образце в результате поглощения излучения эксимерного лазера. Основными параметрами, определяющими начальные условия моделирования процесса лазерного воздействия, являются оптические свойства слоя $(\mathrm{Ga}, \mathrm{Mn}) \mathrm{As}$ в области длины волны излучения эксимерного лазера (коэффициенты отражения и поглощения, потери излучения на рассеяние вследствие наличия шероховатой поверхности), коэффициент теплопроводности и толщина самого слоя [5]. При выполнении настоящей работы исследовались температурные зависимости коэффициента теплопроводности $(k)$ исходных образцов гетеронаноструктур со слоем $(\mathrm{Ga}, \mathrm{Mn})$ As и было установлено, что для температурного диапазона от 20 до $100^{\circ} \mathrm{C}$ коэффициент теплопроводности $(\mathrm{Ga}, \mathrm{Mn}) \mathrm{As}$ в $1.5-2$ раза меньше, чем для GaAs (при температуре $20^{\circ} \mathrm{C} k$ составлял 38.5 и $59 \mathrm{~W} / \mathrm{m} \cdot \mathrm{K}$ для $(\mathrm{Ga}, \mathrm{Mn}) \mathrm{As}$ и $\mathrm{GaAs}$, соответственно). Учет этих данных при расчетах распределения температуры вдоль толщины образца и во времени показал, что в приповерхностном тонком слое $(\mathrm{Ga}, \mathrm{Mn}) \mathrm{As}$ (10-20 nm при полной толщине слоя $110 \mathrm{~nm}$ ) температура вследствие поглощения лазерного излучения может быть близка к температуре плавления GaAs $(1515 \mathrm{~K})$.

Используемые нами слои $(\mathrm{Ga}, \mathrm{Mn}) \mathrm{As}$ вследствие значительного количества марганца могут содержать кластеры полуметалла $\mathrm{MnAs}$, ферромагнитного при комнатной температуре. Это подтверждалось ранее при рентгено-дифракционных исследованиях [13]. Температуpa плавления соединения MnAs эквиатомного состава составляет $936^{\circ} \mathrm{C}(1209 \mathrm{~K})$ [14]. Таким образом, вследствие лазерного воздействия возникают условия, когда температура в области слоя ( $\mathrm{Ga}, \mathrm{Mn}) \mathrm{As}$ значительно превышает указанное значение и поэтому можно ожидать, что включения MnAs c более низкой температурой плавления, чем матрица, могут значительным образом модифицироваться в отожженном образце.
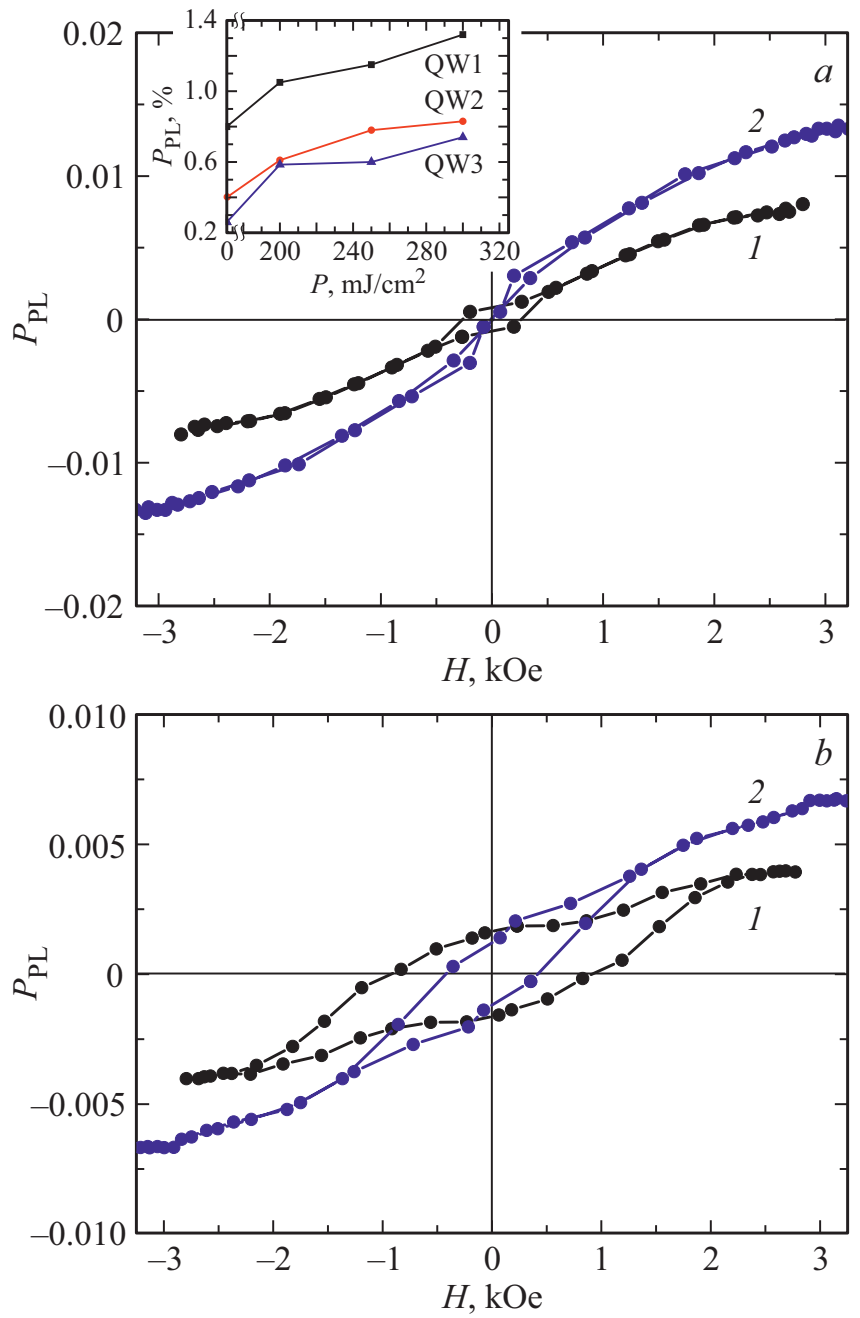

Рис. 6. Магнитополевые зависимости степени циркулярной поляризации фотолюминесцентного излучения (1) исходного образца и (2) образца, отожженного лазерным излучением с $P=300 \mathrm{~mJ} / \mathrm{cm}^{2}$ при температуре $10 \mathrm{~K}$ для КЯ QW1 (часть $a$ ) и КЯ QW2 (часть $b$ ). На вставке показаны зависимости степени циркулярной поляризации от плотности энергии лазерного излучения для квантовых ям QW1, QW2 и QW3 при $10 \mathrm{~K}$ в магнитном поле $2700 \mathrm{Oe}$.

В заключительной части работы обсудим результаты исследования поляризационных характеристик фотолюминесцентного излучения. Для исходных образов структур при $10 \mathrm{~K}$ было зарегистрировано частично циркулярно-поляризованное излучение для трех квантовых ям, расположенных ближе к слою $(\mathrm{Ga}, \mathrm{Mn}) \mathrm{As}$ (рис. 6). Интенсивности излучения KЯ QW4 было недостаточно, чтобы получить достоверные данные о его поляризационных характеристиках. Магнитополевые зависимости степени циркулярной поляризации (PL), приведенные на рисунке для квантовой ямы QW1, являются нелинейными с небольшим гистерезисом $\left(H_{\mathrm{C}} \sim 250 \mathrm{Oe}\right)$. Воздействие лазерного излучения способствует увеличению степени циркулярной поляризации излучения для всех трех КЯ (вставка на рис. $6, a$ ). Величина $P_{\mathrm{PL}}$ для КЯ 
QW1 с энергией основного перехода $1.27 \mathrm{eV}$ возрастает от 0.8 до $1-1.5 \%$ с увеличением плотности энергии излучения при лазерном отжиге, при этом гистерезис на зависимости для отожженного образца не регистрируется. Напротив, зависимости $P_{\mathrm{PL}}(H)$ для более коротковолновой квантовой ямы QW2 (энергия основного перехода $1.33 \mathrm{eV}$ ) в случае исходного и отожженного образцов содержат гистерезис с большой величиной коэрцитивного поля (около 960 Ое для исходного образца).

Полученные магнитополевые зависимости степени циркулярной поляризации фотолюминесценции квантовых ям определяются не только зависимостью намагниченности от магнитного поля, приложенного перпендикулярно слою $(\mathrm{Ga}, \mathrm{Mn}) \mathrm{As}$, но, главным образом, магнитооптическими свойствами $(\mathrm{Ga}, \mathrm{Mn}) \mathrm{As}$ (магнитноциркулярным дихроизмом), имеющими сильную спектральную зависимость. В особенности это характерно для неоднофазных пленок $(\mathrm{Ga}, \mathrm{Mn}) \mathrm{As}$, содержащих включения полуметаллических ферромагнитных соединений (MnAs). В частности, сообщается о присутствии в спектрах экваториального эффекта Керра слоев $(\mathrm{Ga}, \mathrm{Mn}) \mathrm{As}$, изготовленных импульсным лазерным нанесением в аналогичных условиях (температура и содержание $\mathrm{Mn}$ ) сильной резонансной полосы $(E=0.5-2.0 \mathrm{eV})$, связанной с присутствием кластеров MnAs [15].

Можно предположить, что в области излучения длинноволновой квантовой ямы QW1 (около $980 \mathrm{~nm}$ при $77 \mathrm{~K})$ матрица, представляющая собой легированный марганцем GaAs, является почти прозрачной и, таким образом, ее магнитные свойства не оказывают существенного влияния на прошедшее через нее излучение. Остается только вклад от полуметаллических кластеров. В случае квантовой ямы QW2 длина волны излучения уменьшается (до $930 \mathrm{~nm}$ ) и наряду с вкладом в магнитооптические характеристики от полуметаллических включений проявляется влияние матрицы разбавленного магнитного полупроводника.

\section{4. Заключение}

В работе представлены результаты комплексных исследований влияния импульсного лазерного отжига на квантово-размерные структуры InGaAs/GaAs со слоем $(\mathrm{Ga}, \mathrm{Mn}) \mathrm{As}$ в качестве спинового инжектора на поверхности. Показано, что вследствие лазерного воздействия при плотности энергии $\leq 300 \mathrm{~mJ} / \mathrm{cm}^{2}$ сохраняются излучательные свойства активной области структур (квантовой ямы $\mathrm{InGaAs} / \mathrm{GaAs}$ ), расположенной на расстоянии $10-12 \mathrm{~nm}$ от слоя (Ga, Mn)As. При этом фотолюминесцентное излучение квантовой ямы частично циркулярнополяризовано, и степень циркулярной поляризации после импульсного лазерного отжига существенно возрастает. Обнаружено значительное возрастание проводимости структур на всем диапазоне температур измерений (от 10 до $300 \mathrm{~K}$ ) с увеличением плотности энергии лазерного излучения, обусловленное повышением электрической активности примеси $\mathrm{Mn}$ в слое $(\mathrm{Ga}, \mathrm{Mn}) \mathrm{As}$. Поведение магнитополевых зависимостей сопротивления Холла с увеличением температуры и диапазона магнитных полей при измерениях свидетельствует о присутствии в пленке (Ga, Mn)As двух ферромагнитных фаз, отличающихся температурой Кюри.

Для получения расчетных распределений температуры вдоль толщины образца и во времени с применением модели процесса лазерного отжига, основанной на решении задачи о распространении тепла в одномерной GaAs системе с учетом слоя ( $\mathrm{Ga}, \mathrm{Mn}) \mathrm{As}$ на поверхности, были использованы оригинальные данные по коэффициенту теплопроводности структур со слоем $(\mathrm{Ga}, \mathrm{Mn}) \mathrm{As}$, измеренные посредством модифицированной методики частотного разделения ( $3 \omega$-метода). Установлено, что в приповерхностном тонком слое $(\mathrm{Ga}, \mathrm{Mn}) \mathrm{As}(10-20 \mathrm{~nm}$ при полной толщине слоя $110 \mathrm{~nm})$ температура вследствие поглощения лазерного излучения может быть близка к температуре плавления GaAs $(1515 \mathrm{~K})$. Поэтому возникают условия, когда температура в области слоя $(\mathrm{Ga}, \mathrm{Mn}) \mathrm{As}$ значительно превышает температуру плавления возможных присутствующих в нем включений полуметалла $\mathrm{MnAs}(1209 \mathrm{~K})$, и это обстоятельство будет способствовать их значительной структурной модификации, оказывающей влияние на магнитные и магнитооптические свойства структур.

Полученные результаты представляют интерес для развития технологии использования слоев разбавленных магнитных полупроводников в приборах спиновой оптоэлектроники.

\section{Финансирование работы}

Работа выполнена при поддержке РНФ (грант № 19-19-00545, изготовление структур и основные исследования) и (грант № 18-72-10061, исследование поляризационных характеристик фотолюминесценции).

\section{Конфликт интересов}

Авторы заявляют, что у них нет конфликта интересов.

\section{Список литературы}

[1] О.В. Вихрова, Ю.А. Данилов, Б.Н. Звонков, А.В. Здоровейщев, А.В. Кудрин, В.П. Лесников, А.В. Нежданов, С.А. Павлов, А.Е. Парафин, И.Ю. Пашенькин, С.М. Планкина. ФТТ 59, 11, 2130 (2017).

[2] W. HaiLong, C. Lin, Z. JianHua. Sci. China Phys. Mech. Astronomy 56, 1, 99 (2013).

[3] Sh.U. Yuldasheva, Z.A. Yunusova, Y.H. Kwonb, S.H. Leec, R. Ahujad, T.W. Kanga. Solid State Commun. 263, 38 (2017).

[4] Y. Jiang, Y.Ji, N. Li, J. Guo, Y. Yuan, W. Liang, H. Yang. AIP Advances 11, 025011 (2021).

[5] О.В. Вихрова, Ю.А. Данилов, Б.Н. Звонков, И.Л. Калентьева, Ю.М. Кузнецов, А.В. Нежданов, А.Е. Парафин, Д.В. Хомицкий, И.Н. Антонов. ФТТ 63, 3, 346 (2021). 
[6] R.T. Blunt. CS MANTECH Conference. (April 24-27, 2006). Vancouver, British Columbia, Canada. P. 59.

[7] D.J. Kim, D.S. Kim, S. Cho, S.W. Kim, S.H. Lee, J.C. Kim. Int. J. Thermophys. 25, 281 (2004).

[8] W. Limmer, M. Glunk, S. Mascheck, A. Koeder, D. Klarer, W. Schoch, K. Thonke, R. Sauer, A. Waag. Phys. Rev. B 66, 205209 (2002).

[9] M.J. Seong, S.H. Chun, H.M. Cheong, N. Samarth, A. Mascarenhas. Phys. Rev. B 66, 033202 (2002).

[10] Э.Л. Нагаев. Физика магнитных полупроводников. Наука, M. (1979).

[11] L.H. Bennetta, E.D. Torre. J. App. Phys. 97, 10E502 (2005).

[12] K.Y. Wang, K.W. Edmonds, R.P. Campion, L.X. Zhao, C.T. Foxon, B.L. Gallagher. Phys. Rev. B 72, 085201 (2005).

[13] Б.Н. Звонков, О.В. Вихрова, Ю.А. Данилов, Ю.Н. Дроздов, А.В. Кудрин, М.В. Сапожников. ФТТ 52, 11, 2124 (2010).

[14] J. Paitz. Kristall Tech. 7, 9, 999 (1972).

[15] 3.Э. Кунькова, Е.А. Ганьшина, Л.Л. Голик, Ю.А. Данилов, А.В. Кудрин, В.И. Ковалев, Г.С. Зыков, Ю.В. Маркин, О.В. Вихрова, Б.Н. Звонков. ФТП 60, 5, 940 (2018).

Редактор Ю.Э. Китаев 